\title{
In silico assessment of the druggability of two novel germacranolides isolated from Capparis decidua (Forsk.) as carbonic anhydrase II inhibitors
}

\author{
Magdi A. Mohamed ${ }^{1 *}$, Amina I. Dirar ${ }^{1,2}$, Mohamed A. A. Elbadawi ${ }^{3}$, Wadah J. A. Osman ${ }^{4}$, Mona S. Mohammed ${ }^{4}$, \\ Sami Hamdoun ${ }^{5}$ \\ ${ }^{1}$ Department of Pharmaceutical Chemistry, Faculty of Pharmacy, University of Khartoum, Sudan. ${ }^{2}$ Department of Phytochemistry and Plant Sciences, \\ Faculty of Pharmacy, National University, Sudan. ${ }^{3}$ Department of Pharmacology, Faculty of Pharmacy, University of Khartoum, Sudan. ${ }^{4}$ Department of \\ Pharmacognosy, Faculty of Pharmacy, University of Khartoum, Sudan. ${ }^{5}$ Department of Pharmaceutics, Faculty of Pharmacy, University of Khartoum, \\ Sudan.
}

\begin{tabular}{|c|c|}
\hline ARTICLE INFO & ABSTRACT \\
\hline Article history: & \multirow{7}{*}{$\begin{array}{l}\text { Novel naturally derived molecules are frequently isolated from different plants with endued biological activities. } \\
\text { Nevertheless, druggability studies for most of these molecules have been put on hold due to, in part, the limited } \\
\text { quantity of material available from isolation and the expensive lengthy drug development process in the other } \\
\text { part. In silico drug discovery has always been an effective approach to reduce the cost and time needed to bring } \\
\text { a drug to the market. In the current study, Autodock } 4.0 \text { software along with different chemoinformatic tools, } \\
\text { namely, PharmMapper, Molinspiration, Metaprint } 2 \mathrm{D} \text { and AdmetSAR servers were used to assess the } \\
\text { druggability of two novel germacranolides isolated from Capparis decidua (Forsk.). Our findings revealed that } \\
\text { these two isolates are potential carbonic anhydrase II (CA II) inhibitors. Interestingly, inhibition of CA II is } \\
\text { known to have a vital role in curing different diseases, e.g. neuropathic pain, bipolar disorder, migraine, obesity, } \\
\text { osteoporosis and most interestingly tumor. Thus, the two germacranolides could be envisioned as promising } \\
\text { drug candidates for curing these aforementioned disorders. }\end{array}$} \\
\hline Received on: $31 / 07 / 2016$ & \\
\hline Revised on: 18/08/2016 & \\
\hline Accepted on: 16/09/2016 & \\
\hline Available online: $31 / 01 / 2017$ & \\
\hline Key words: & \\
\hline $\begin{array}{l}\text { Capparis decidua (Forsk.), } \\
\text { germacranolides, } \\
\text { chemoinformatics, carbonic } \\
\text { anhydrase II, tumor. }\end{array}$ & \\
\hline
\end{tabular}

\section{INTRODUCTION}

Conventional drug discovery is challenging, time consuming, expensive and requires consideration of many aspects that have a negative impact on the pharmaceutical industry (Earm and Eram, 2014). Interestingly, In silico drug discovery has nowadays surpassed the conventional approach where potential biological activity and druggability of a new lead could be estimated computationally at an early stage, shortening the time needed to bring the drug to the market (Sliwoski et al., 2014). As an important source of drug discovery, medicinal plants have always played a key role in curing diseases. In this context, Capparis decidua Family (Capparidaceae) is not an exception where different parts of this plant were used by ancient people for medicinal purposes (Nizar et al., 2011). The plant is

* Corresponding Author

Email: mawadalla@uofk.edu widely distributed in Sudan and other countries where it has many traditional uses for the control of various ailments (Al-Yahya 1986; Shah et al., 1989; Elamin 1990; Elkamali and Elkhalifa 1999; Atiqur et al., 2004; Khalid et al., 2012). Most importantly, the plant has also been used as a diuretic (Verma et al., 2011). Diuretics are drugs used extensively for the treatment of various medical disorders (Brater, 2000). All diuretics act mainly by impairing $\mathrm{Na}^{+}$re-absorption in the renal tubules. However, they differ significantly in their chemical structures, mechanism and site of action. Carbonic anhydrases are highly expressed and distributed through the nephrons where they play a fundamental role in the renal acid-base homeostasis control, bicarbonate reabsorption and ammonium excretion (Hassan et al., 2012). Thus, carbonic anhydrase inhibitors such as acetazolamide produce their diuretic action through interference with the enzyme activity both within the brush border and inside the cell, resulting in impaired $\mathrm{NaHCO}_{3}$ and water re-absorption (Carta et al., 2014). 
Mohammed and co-workers have isolated and characterized two novel germacranolides (1 and 2; Fig. 1) from $C$. decidua (Mohammed et al., 2012; Mohammed et al., 2014). Being involved in drug discovery from medicinal plants (Dirar et al., 2014; Dirar et al., 2016; Mohamed et al., 2016), we herein report the In silico druggability of these novel isolates as CA II inhibitors.

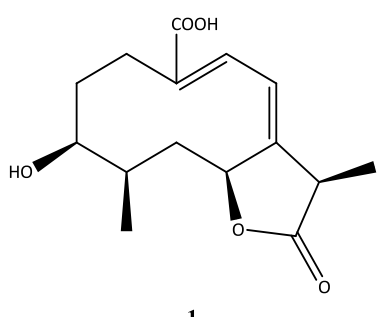

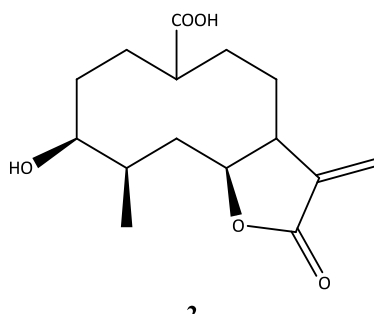

Fig. 1

\section{MATERIALS AND METHODS}

General

ChemDraw Ultra 12 software was used to prepare the compounds' 3D structures which were saved as PDB format. On the other hand, MDL.sdf and SMILE formats were generated using Open Bable software (O'Boyle et al., 2011). The manually optimized protein 3D structure was retrieved from protein data bank. Manual energy minimization was conducted on the Swiss PDB viewer V.4.1.0. software (Guex and Peitsch, 1997). Molecular docking was performed using Autodock 4.0 software based on Lamarckian Genetic Algorithm (Morris et al., 1998; Morris et al., 2009).

\section{Prediction of biological activity}

PharmMapper server was used to predict the potential protein target for germacranolides $\mathbf{1}$ and 2. On the other hand, Molinspiration server was used to predict drug likeness properties of these leads as G-protein coupled receptor (GPCR) ligands, ion channel modulators (ICM), kinase inhibitors (KI), nuclear receptor ligands (NRL), protease inhibitors (PI) and enzyme inhibitors (EI).

\section{Molecular docking}

The 3D structures of the two germacranolides were prepared according to the standard docking protocol. The cocrystal ligand was removed from the protein target which was then prepared according to the standard docking protocol. The UniProt databases were used to verify the active site. The target's grid map was calculated and set to $60 \times 60 \times 60$ points with grid spacing of $0.375 \AA$ to assure that all the active residues were included in the center. The default docking algorithms were set in accordance with the standard docking protocol.

Finally, ten independent docking runs were carried out for each ligand and results were retrieved as binding energies.
Poses that showed lowest binding energies were visualized using MOE (Available at: http://www.chemcomp.com) [Accessed 17 May 2016] and UCSF chimera (Pettersen et al., 2004).

\section{Physicochemical properties}

Molinspiration server was used to estimate different physicochemical properties, namely LogP, Topological polar surface area (TPSA) and number of hydrogen bond donors (HBD) and acceptors (HBA) for germacranolides $\mathbf{1}$ and $\mathbf{2}$.

\section{Metabolic transformations and toxicity}

MetaPrint2D online server was used to predict the metabolic sites and transformations for germacranolides $\mathbf{1}$ and $\mathbf{2}$. AdmetSAR server was used to assess the potential toxicity of these isolates.

\section{RESULTS AND DISCUSSION}

PharmMapper server has predicted that carbonic anhydrase II (CA II; PDB ID: 1G48) (Kim et al., 2000) is the best target, in terms of fit score, for our isolates $\mathbf{1}$ and $\mathbf{2}$ (3.887 and 3.160 , respectively). The CA II is involved in many physiological and pathological processes (Supuran, 2008). For example, it facilitates electrolyte secretion in addition to transportation of $\mathrm{CO}_{2}$ and bicarbonate between metabolic sites and lungs resulting in controlled respiration. Furthermore, CA II has a major role in $\mathrm{pH}$ and $\mathrm{CO}_{2}$ homeostasis (Hassan et al., 2012). Moreover, it plays a vital role in the biosynthesis of glucose, lipids and urea (Supuran, 2008).

Thus, CA II inhibitors are prescribed clinically as diuretics and for glaucoma (Supuran et al., 2003). In addition, these inhibitors were proved to have potential therapeutic uses for neuropathic pain, bipolar disorder, migraine, obesity, osteoporosis, epilepsy and tumor (Scozzafava et al., 2006; Thiry et al., 2006; Riihonen et al., 2007). With CA II, as a potential target for our germacranolides $\mathbf{1}$ and $\mathbf{2}$, in hand, we next decided to investigate the course of the biochemical interactions of these two isolates with CA II active site which was verified from UniProt databases. Molecular docking revealed interesting interactions between the two isolates and CA II with satisfactory binding energies ( -6.94 and $-9.31 \mathrm{Kcal} / \mathrm{mol}$, respectively). Germacranolide $\mathbf{1}$ forms a hydrogen bond with the key residue His 64, which is involved in the proton-shuttling processes between the active site and the environment (Fig. 2).

The interaction of germacranolides 1 with His 64 could therefore have an inhibitory role in regeneration of the basic active form of CA II (Supuran and Scozzafava, 2007). Additionally, the predicted hydrogen bonds with the residues Asn 62, Asn 67, Gln 92 and Thr 200 could potentiate such an inhibitory role as these residues have been reported to interact with some CA II inhibitors (Supuran et al., 2003; Supuran and Scozzafava, 2007). Germacranolide 2, on the other hand, forms hydrogen bonds with the key residues His 94, His 96 and His 119 whose interaction with $\mathrm{Zn}$ metal is crucial for enzyme's activity (Fig. 2). 

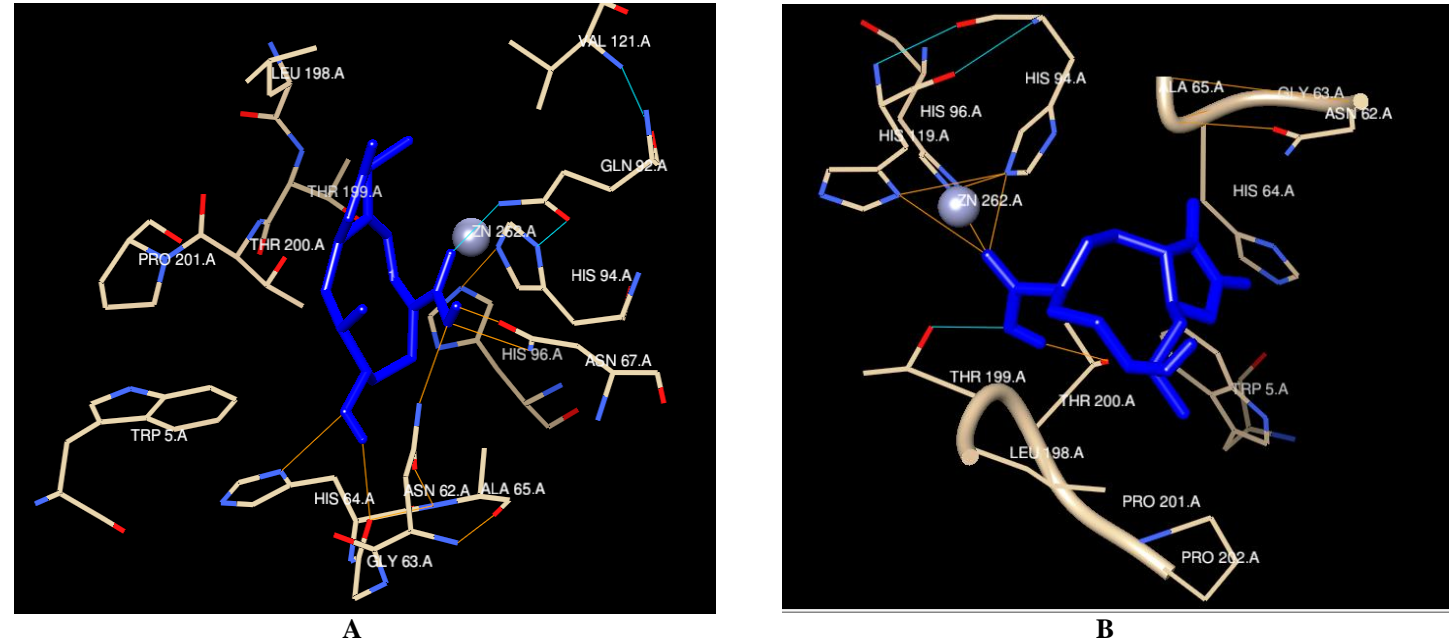

$\mathbf{B}$
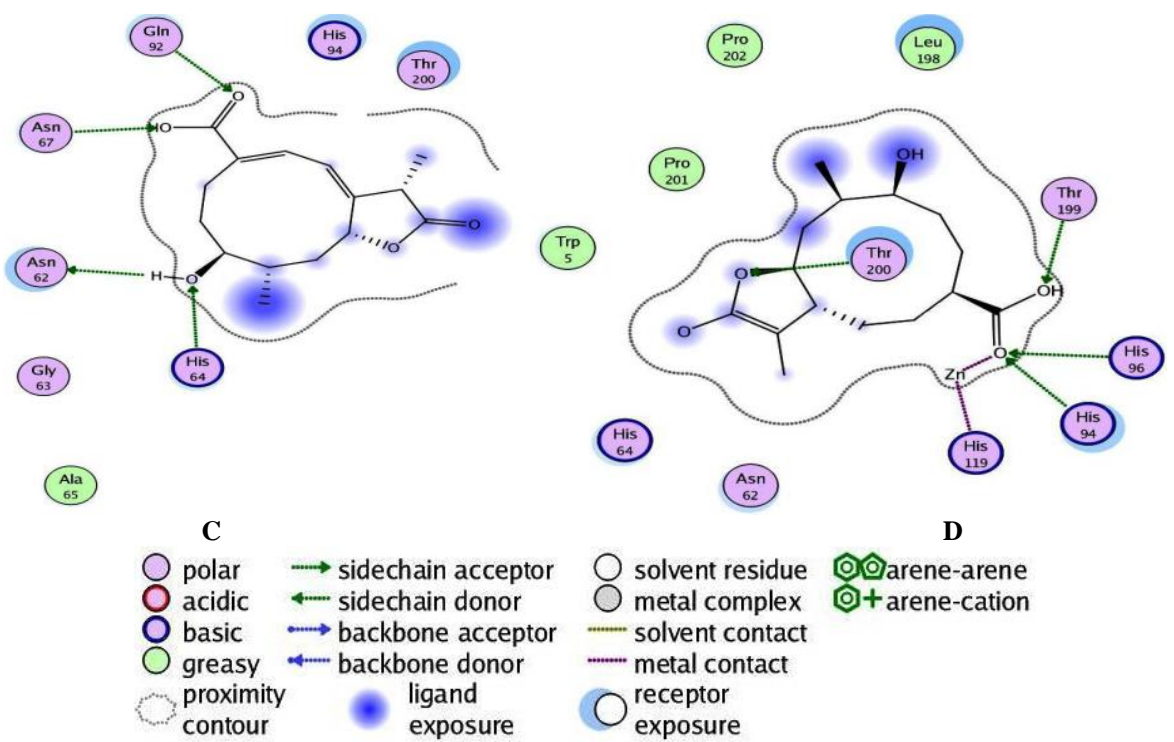

Fig. 2: Ligand-Carbonic anhydrase II interactions.

Germacranolide 1-CA II interactions visualized by (a) Chimera and (c) MOE. Germacranolide 2-CA II interactions visualized by (b) Chimera and (d) MOE.

As for the other inhibitors, interaction of germacranolide 2 with the aforementioned key residues would contribute very much to its potential CA II inhibitory effect (Supuran, 2008). In addition, germacranolide $\mathbf{2}$ could potentially inhibit bicarbonate formation via hydrogen bond interaction with the key residue Thr 199 which is known to facilitate the nucleophilic attack of water on carbon dioxide (Supuran , 2008). Moreover, germacranolide 2, binds two hydrophobic residues, namely Leu 198 and Pro 202 (Supuran and Scozzafava, 2007). It is worth noting that these two residues are part of the hydrophobic pocket where $\mathrm{CO}_{2}$ resides before it interacts with Zn-bound water (Pastorekova et al., 2004). Based on Lipinski's rule of five (Lipinski et al., 2001), our isolates $\mathbf{1}$ and $\mathbf{2}$ were predicted to have good oral bioavailability, where the estimated $\log \mathrm{P}$ values, the number of hydrogen bond acceptors (HBA) and number of hydrogen bond donors (HBD) were found within the limited range. In addition, Total Polar Surface Area
(TPSA), total hydrogen bond count, number of rotatable bonds and molecular weights were found to be within the limit stated (Table 1) (Lipinski et al., 2001; Veber et al., 2002; Srimai et al., 2013).

Table 1: Physicochemical parameters predicted by Molinspiration.

\begin{tabular}{ccccccc}
\hline Compound & Mi $\log P$ & TPSA & MW & HBA & HBD & nrotb \\
\hline $\mathbf{1}$ & 0.30 & 83.83 & 280.32 & 5 & 2 & 1 \\
$\mathbf{2}$ & 0.51 & 83.83 & 282.34 & 5 & 2 & 1 \\
\hline
\end{tabular}

Regarding drug likeliness properties, germacranolides $\mathbf{1}$ and 2 were predicted to have high activity (values >0.00) as GPCR ligands, ICMs, NRLs, PIs and EIs (Paramashivam et al., 2015). Nonetheless, both compounds were found to be moderately active as KI (values $=-0.22$ and -0.25 , respectively) (Table 2). 
Table 2: Drug likeliness property estimations by Molinspiration.

\begin{tabular}{cccccc}
\hline Compound & GPCR $^{*}$ & ICM $^{*}$ & KI $^{*}$ & NRL $^{*}$ & PI $^{*}$ \\
\hline $\mathbf{1}$ & 0.26 & 0.42 & -0.22 & 0.46 & 0.28 \\
EI $^{*}$ & 0.17 & -0.25 & 0.83 & 0.26 & 0.68 \\
\hline values $>0.00$ indicate high activity; values between 0.00 to -0.5 indicate moderate activity; values $<-0.5$ indicate inactivity.
\end{tabular}
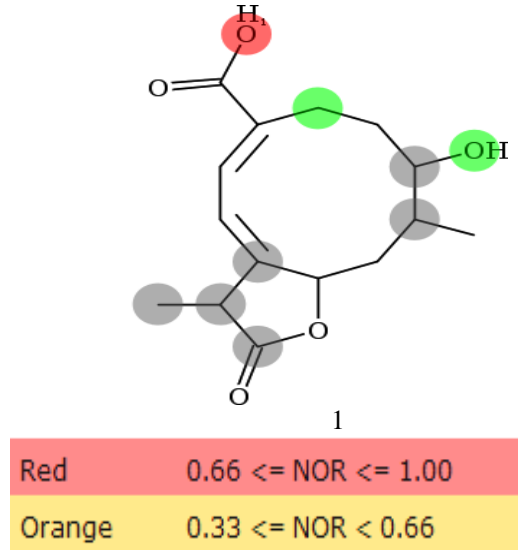

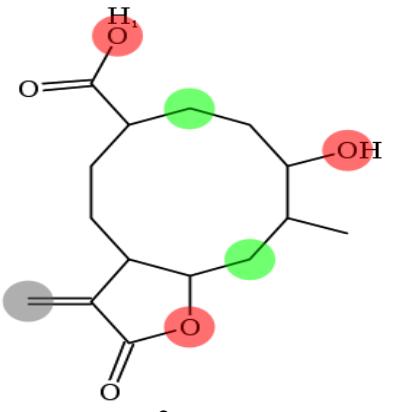

2

$\begin{array}{ll}\text { Green } & 0.15<=\text { NOR }<0.33 \\ \text { White } & 0.00<=\text { NOR }<0.15 \\ \text { Grey } & \text { Little/no data }\end{array}$

Fig. 3: Metabolic predictions using Metaprint2D for tested compounds.

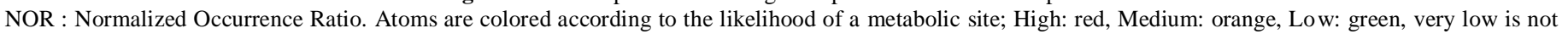
colored, and No data: grey.

Based on Normalized Occurrence Ratio (NOR), the Metaprint2D-predicted metabolic transformations revealed that the hydroxyl group of the carboxylic acid represents a good site for phase II metabolism in both compounds. In this context, glucuronidation, alkylation, esterification and sulfation were predicted for germacranolides $\mathbf{1}$ and $\mathbf{2}$. In addition, glycination, dehydroxylation, phosphorylation and glutamination were predicted for $\mathbf{2}$. Contrary to $\mathbf{2}$, germacranolide $\mathbf{1}$ was also predicted to undergo metabolic transformation (with high NOR) at two additional sites, namely the secondary alcohol and the lactone moiety. While only dealkylation was predicted for the lactone oxygen, seven transformations were predicted for the secondary alcohol; these are glucuronidation, oxidation, sulfation, acylation, glucosidation, methylation and acetylation (Fig. 3). The toxicity of the two leads was estimated by AdmetSAR. Interestingly, neither carcinogenicity nor mutagenicity were predicted for germacranolides $\mathbf{1}$ or $\mathbf{2}$.

\section{CONCLUSION}

The In silico assessment of the druggability for two novel germacranolides isolated from Capparis decidua (Forsk.) has been addressed in this study. Both compounds have been proved to be potential drug candidates for curing different diseases, e.g. tumors, through CA II inhibitory mechanism.

\section{ACKNOWLEDGEMENTS}

All authors acknowledge Faculty of Pharmacy, University of Khartoum, SUDAN for support and assistance.
Financial support and sponsorship: Amina I. Dirar acknowledges the partial financial support provided by the National University, SUDAN.

Conflict of Interests: There are no conflicts of interest.

\section{REFERENCES}

Al-Yahya M. Phytochemical studies of the plants used in traditional medicine of Saudi Arabia. Fitoterapia, 1986; 3:179-182.

Atiqur R, Mossa J, AL-Said M, AL-Yahya M. Medicinal plant diversity in the flora of Saudi Arabia 1: a report on seven plant families. Fitoterapia, 2004; 75:149-161. 319:38-50.

Brater DC. Pharmacology of diuretics. Am J Med Sci, 2000;

Carta F, Supuran CT, Scozzafava A. Sulfonamides and their isosters as carbonic anhydrase inhibitors. Future Med Chem, 2014; 6:1149-1165

Dirar AI, Mohamed MA, Ismail EMO, Khalid HS, Elfatih F, Khalid A. In silico molecular docking of Di-(2-ethylhexyl) phthalate and 13-Hexyloxyacylcyclotridec-10- en-2-one identified in Ambrosia maritima L. (Asteraceae). WJPR, 2014; 3:08-16.

Dirar AI, Mohamed MA, Khalid HS, Osman B, Fadul E, Khalid A. In vitro antioxidant activity and phytochemical profile of three antitumor medicinal plants grown in Sudan. WJPR, 2014; 3:136-142.

Dirar AI, Mohamed MA, Osman B, Khalid HS, Ismail E MO, Mohamed M S. Pharmacological studies on four anti-tumor medicinal plants grown in Sudan. IJRPC, 2014; 4:1004-1008.

Dirar AI, Mohamed MA, Osman WJA, Mohammed MS, Khalid HS, Garelnabi EAE. Isolation and characterization of potential cytotoxic leads from Ambrosia maritima L. (Asteraceae). Journal of Pharmacognosy and Phytochemistry, 2014; 3:38-41.

Dirar AI, Waddad AY, Mohamed MA, Mohamed MS, Osman WJA, Mohammed MS, Elbadawi MAA, Hamdoun S. In silico pharmacokinetic and molecular docking of three leads isolated from Tarconanthus camphoratus L. Int J Pharm Pharm Sci, 2016; 8:71-77. 
Earm K, Earm YE. Integrative approach in the era of failing drug discovery and development. Integr Med Res, 2014; 3:211-216.

Elamin HM. 1990. Trees \& Shurbs of the Sudan. London. UK: Ithaca Press. Exeter.

Elkamali HH, Elkhalifa KF. Folk medicinal plants of riverside forests of the Southern Blue Nile district, Sudan. Fitoterapia, 1999; 70:493-497.

Guex N, Peitsch MC. SWISS-MODEL and the SwissPdbViewer: an environment for comparative protein modeling. Electrophoresis, 1997; 18:2714-2723.

Hassan MI, Shajee B, Waheed A, Ahmad F, Sly WS. Structure, function and applications of carbonic anhydrase isozymes. Bioorg Med Chem, 2013; 21:1570-1582.

Khalid H, Abdalla WE, Abdelgadir H, Opatz T, Efferth T. Gems from traditional north African medicine: medicinal and aromatic plants from Sudan. Nat Prod Bioprospect, 2012; 2:92-103.

Kim CY, Chang JS., Doyon JB, Baird TT., Jr., Fierke CA, Jain A, Christianson DW. Contribution of fluorine to protein-ligand affinity in the binding of fluoroaromatic inhibitors to carbonic anhydrase II. J Am Chem Soc, 2000; 122:12125-12134.

Lipinski CA, Lombardo F, Dominy BW, Feeney PJ. Experimental and computational approaches to estimate solubility and permeability in drug discovery and development settings. Adv Drug Deliv Rev, 2001;46:3-26.

Mohamed MA, Dirar AI, Hamdoun S. Discovery of two diacetylene glycosides as human uridine-cytidine kinase 2 inhibitors: an In silico approach. J App Pharm Sci, 2016 (accepted).

Mohammed MS, Khalid HS, Muddathir AK, Siddiqui NA, Ali M. A novel germacranolide sesquiterpene lactone with antiinflammmatory effect from Capparis decidua (Forsk.). IJRPC, 2012; 2:1073-1077.

Mohammed MS, Khalid HS, Muddathir AK, El Tahir KEH, Osman B, Osman WJA, Basudan O. Effect of two sesquiterpene lactones from Capparis decidua (Forsk.) on arachidonic acid and adenosine diphosphate-induced platelets aggregation. The Journal of Phytopharmacology, 2014; 3:1-4.

Morris GM, Goodsell DS, Halliday RS, Huey R, Hart WE, Belew RK, Olson AJ. Automated docking using a Lamarckian genetic algorithm and empirical binding free energy function. J Comput Chem, 1998; 19:1639-1662.

Morris GM, Huey R, Lindstrom W, Sanner MF, Belew RK, Goodsell DS, Olson AJ. Autodock4 and AutoDockTools4: automated docking with selective receptor flexiblity. J Comput Chem, 2009; 30:2785-2791.

Nizar T, Walid E, Ezzeddine S, Abdelhamid K, Saida T, Nizar N. The caper (Capparis L.): Ethnopharmacology, phytochemical and pharmacological properties. Fitoterapia, 2011; 82: 93-10.

O'Boyle NM, Banck M, James CA, Morley C, Vandermeersch T, Hutchison GR. Open Babel: an open chemical toolbox. Journal of Cheminformatics, 2011; 3:33. [ONLINE] Available at: http://www.jcheminf.com/content/3/1/33. [Accessed 04 June 2016].

Paramashivam SK, Elayaperumal K, Natarajan BB, Ramamoorthy $\mathrm{MD}$, Balasubramanian $\mathrm{S}$, Dhiraviam $\mathrm{KN}$. In silico pharmacokinetic and molecular docking studies of small molecules derived from Indigofera aspalathoides Vahl targeting receptor tyrosine kinases. Bioinformation, 2015; 11:73-84.
Pastorekova S, Parkkila S, Pastorek J, Supuran CT. Carbonic Anhydrases: Current state of the art, therapeutic applications and future prospects. J Enz Inh Med Chem, 2004; 19:199-229.

Pettersen EF, Goddard TD, Huang CC, Couch GS, Greenblatt DM, Meng EC, Ferrin TE. UCSF Chimera-a visualization system for exploratory research and analysis. J Comput Chem, 2004; 25:1605-1612.

Riihonen R, Supuran CT, Parkkila S, Pastorekova S, Väänänen HK, Laitala-Leinonen T. Membrane-bound carbonic anhydrases in osteoclasts. Bone, 2007; 40:1021-1031.

Scozzafava A, Mastrolorenzo A, Supuran CT. Carbonic anhydrase inhibitors and activators and their use in therapy. Expert Opin Ther Patents, 2006; 16:1627-1664.

Shah AH, Tariq M A, Qureshi S. Cytological studies on some plants used in traditional Arab medicine. Fitoterapia, 1989; 60:171-173.

Sliwoski G, Kothiwale S, Meiler J, Lowe EW Jr. Computational methods in drug discovery. Pharmacol Rev, 2014; 66:334-395.

Srimai V, Ramesh M, Parameshwar KS, Parthasarathy T. Computer-aided design of selective cytochrome P450 inhibitors and docking studies of alkyl resorcinol derivatives. Med Chem Res, 2013; 22:5314-5323.

Supuran CT. Carbonic anhydrases: novel therapeutic applications for inhibitors and activators. Nat Rev Drug Discov, 2008; 7:168-181.

Supuran CT. Carbonic Anhydrases An Overview. Curr Pharm Design, 2008; 14:603-614

Supuran CT, Scozzafava A. Carbonic anhydrases as targets for medicinal chemistry. Bioorg Med Chem, 2007; 15:4336-4350.

Supuran CT, Scozzafava A, Casini A. Carbonic anhydrase inhibitors. Med Res Rev, 2003; 23:146-189.

Thiry A, Dogne JM, Masereel B, Supuran CT. Targeting tumorassociated carbonic anhydrase IX in cancer therapy. Trends Pharmacol Sci, 2006; 27:566-573.

Veber DF, Johnson SR, Cheng HY, Smith BR, Ward KW, Kopple KD. Molecular properties that influence the oral bioavailability of drug candidates. J Med Chem, 2002; 45:2615-2623.

Verma PD, Dangar RD, Shah KN, Gandhi DM, Suhagia BN. Pharmacognostical potential of Capparis decidua Edgew. J Appl Pharm Sci, 2011; 1:6-11.

Yang C, Li Q, Li Y. Targeting Nuclear Receptors with Marine Natural Products. Mar Drugs, 2014; 12:601-635.

\section{How to cite this article:}

Mohamed MA, Dirar AI, Elbadawi MAA, Osman WJA, Mohammed MS, Hamdoun S. In silico assessment of the druggability of two novel germacranolides isolated from Capparis decidua (Forsk.) as carbonic anhydrase II inhibitors. J App Pharm Sci, 2017; 7 (01): 093-097. 